\title{
IgA antibodies in human milk: epidemiological markers of previous infections?
}

\author{
K A Nathavitharana, D Catty, A S McNeish
}

\begin{abstract}
The concept of an enteromammary link in secretory IgA (SIgA) antibody production was tested by hypothesising that specific SIgA antibody profiles in human milk might be an epidemiological marker for enteropathogens in a community. Milk from three subject groups was studied: 64 Sri Lankan women living in poor suburbs of Colombo, 20 Asian immigrant women domiciled in Birmingham, for a median period of five years (range 14 days16 years), and 75 white women living in Birmingham. An enzyme linked immunosorbent assay (ELISA) was developed for the detection and measurement of SIgA antibodies to a panel of 14 crude $O$ and 10 pure lipopolysaccharide antigens of diarrhoeagenic Escherichia coli strains well known to be endemic in the Indian subcontinent.
\end{abstract}

The number of Sri Lankan and Asian immigrant women with SIgA antibodies to all 14 diarrhoeagenic $E$ coli antigens (except 0127 in Asian women) was significantly higher than in the white controls. The amount of $E$ coli $O$ antigen specific SIgA antibody activity as a percentage of total SIgA also gave significantly higher median values in Sri Lankan $(6 \%)$ and in Asian immigrant (4\%) women than in white controls $(0.7 \%)$. SIgA antibodies were highly $O$ serogroup specific and showed excellent concordance between crude $O$ and the corresponding purified lipopolysaccharide antigens. These results suggest that milk antibody profiles represent an epidemiological marker of exposure to enteral pathogens. The continuing specific milk antibody response in Asian women who have been domiciled in the United Kingdom for many years may indicate 'memory' in the human secretory immune system.

(Arch Dis Child 1994; 71: F192-F197)

Secretory $\operatorname{IgA}(\mathrm{S} \operatorname{IgA})$ is the predominant immunoglobulin in human milk. The mammary gland, which is not designed for antigen handling, is an important effector organ of the secretory immune system. Evidence from several animal species strongly suggests that immunoglobulin secreting cells in the mammary gland originate from the gut. ${ }^{1-5}$ Sensitised lymphocytes generated by the gut associated lymphoid tissues appear to resettle or home in on exocrine glandular tissues such as the mammary gland..$^{6-8}$ This phenomenon has been shown to be under the influence of hormonal ${ }^{4}$ and other chemotactic factors. ${ }^{9}$ Human milk has been shown to contain antibodies to a variety of dietary antigens ${ }^{1011}$ and enteric micro-organisms, ${ }^{12-22}$ lending further support to the concept of an enteromammary link in SIgA antibody production.

In this study we hypothesised that the specific SIgA antibody profile in human milk might serve as an epidemiological marker for the presence of specific enteropathogens in a community. Using diarrhoeagenic Escherichia coli as an infection model we examined specific SIgA antibody profiles in milk from three groups of lactating women from widely different backgrounds and environments: Sri Lankan women living in Sri Lanka, Asian immigrant women living in Birmingham, and white women living in Birmingham, representing groups with presumed continuing high exposure, high exposure in the past, and minimal or no exposure to diarrhoeagenic $E$ coli, respectively.

\section{Subjects and methods}

The study was approved by the research and ethical committee of the Birmingham Maternity Hospital. Informed consent was obtained from all subjects.

\section{SUBJECTS}

The study group(s) comprised 64 Sri Lankan women and 20 first generation Asian immigrant women living in Birmingham. The 'control' group consisted of 75 white women living in Birmingham (table 1 ).

MILK SAMPLE COLLECTION, TRANSPORT, PREPARATION, AND STORAGE

The study was on single samples and was cross sectional. Milk specimens $(5-10 \mathrm{ml})$ were collected randomly at any time point during lactation (table 1). All subjects had delivered at term. Most $(>90 \%)$ samples were expressed manually. A few samples were expressed using

a breast pump. Most samples were frozen at

*These women were from the following countries: Pakistan, nine; India, eight; Bangladesh, two; and Sri Lanka, one.

†Duration of residence in the UK: median, five years; range 14 days-16 years. 
$-20^{\circ} \mathrm{C}$ immediately after collection, but some were refrigerated at $4^{\circ} \mathrm{C}$ for up to four hours after collection before being frozen. The samples from Sri Lanka were collected from women in the postnatal wards of the Kotte Sri Jayawardanepura Hospital, De Soyza Maternity Hospital, Colombo, Base Hospital, Kalutara, and from women living close to these hospitals. They were stored frozen at $-20^{\circ} \mathrm{C}$ for up to two weeks and transported on dry ice by one of us (KAN). All the other samples were collected from women in the Birmingham Maternity Hospital and donor mothers of the Sorrento Milk Bank, Birmingham. After thawing and centrifugation $(10000 \times g$ for 30 minutes at $4^{\circ} \mathrm{C}$ ), the soluble interphase between the cell pellet and the lipid layer at the top was stored at $-20^{\circ} \mathrm{C}$ until analysis.

DIARRHOEAGENIC E COLI ANTIGENS

A panel of 14 individual $E$ coli strains representing enteropathogenic (O55, O111, O119, O125, O127, O128, O142), enterotoxigenic (O6, O27, O78, O148, O159), enteroinvasive (O124), and enterohaemorrhagic (O26) serotypes were obtained from the division of enteric pathogens, Central Public Health Laboratory, Colindale Avenue, London. Crude $\mathrm{O}$ antigens were prepared by heat treatment of bacterial suspensions $\left(10^{5} / \mathrm{ml}\right)$ according to standard methods. ${ }^{23}$ Purified lipopolysaccharides of 10 diarrhoeagenic $E$ coli (O55, O111, O119, O125, O127, O128, $\mathrm{O} 142, \mathrm{O} 6, \mathrm{O} 124$, and $\mathrm{O} 26)$ were generously donated by Drs K Jann and B Jann, Max Planck-Institut für Immunobiologie, Freiburg, Federal Republic of Germany. Freeze dried preparations of lipopolysaccharide were reconstituted to $1 \mathrm{mg} / \mathrm{ml}$.

ELISA FOR MEASUREMENT OF TOTAL SIgA ANTIBODIES IN HUMAN MILK

The ELISA plates (Nunc Immunoplate, Gibco Europe, Paisley, UK) were coated with $2 \mu \mathrm{g} / \mathrm{ml}$ of $\alpha$ chain specific sheep IgG raised against human IgA. After overnight incubation and washing, a purified SIgA standard (purified by Sephadex G-200 column separation of a colostral euglobulin precipitate) in doubling dilutions, starting at a concentration of $20 \mu \mathrm{g} / \mathrm{ml}$, was added to antigen standard wells. Human milk samples in serial dilutions starting at $1 / 50$ were added to test wells. The next layer was antisecretory component specific sheep IgG raised against human SIgA and conjugated to horseradish peroxidase in our laboratory (dilution $1 / 10^{4}$ ). After further incubation and washing, the reaction was developed with freshly prepared substrate (ortho-phenylenediamine). The enzyme substrate reaction was stopped with $20 \%$ sulphuric acid after 30 minutes. The absorbance of the contents of each well was measured at $492 \mathrm{~nm}$ in an ELISA plate reader (Titertek Multiscan MCC, Flow Laboratory). The SIgA concentration of milk specimens was determined by comparing their absorbance with the linear part of a standard curve for pure SIgA antibody. ${ }^{24}$ In quality control experiments, purified monomeric IgA (7S), serum IgM, and IgG did not give a positive binding and did not interfere with the specificity of this assay.

\section{ELISA FOR DETECTION OF E COLI O ANTIGEN} SPECIFIC SIgA ANTIBODIES

The ELISA plates were coated overnight with crude $E$ coli $O$ antigen diluted to $1 / 10$ (or $1 \mu \mathrm{g} / \mathrm{ml}$ of lipopolysaccharide). The plates were washed and dried the next day. The next layer consisted of the milk specimens to be tested (dilution 1/10). After incubation and washing, the conjugate (sheep anti-human SIgA-horseradish peroxidase) was added (dilution $1 / 10^{4}$ ). Substrate was added after further incubation, washing, and drying. The colour reaction was stopped with sulphuric acid after 30 minutes and the absorbance of the contents of each well was measured. Control wells without an intermediary milk layer produced an absorbance of $<0.2$ units. Twenty five control milk specimens (the samples from white women) produced a mean (2SD) absorbance of 0.25 units. Therefore an absorbance of $>0.25$ units was considered to be indicative of the presence of specific SIgA antibody to a given $E$ coli crude $O$ antigen or lipopolysaccharide. Non-specific binding was much lower in assays where lipopolysaccharide was used to coat the plates.

All milk specimens were tested in duplicate and were always tested with known positive and negative controls concurrently. All assays were sensitive and specific. The day to day and within plate variations were small (coefficient of variation $5 \%$ or less).

\section{ASSAYS FOR TESTING O SEROGROUP} SPECIFICITY OF SIgA ANTIBODIES

Twenty milk samples (from 15 Sri Lankan and five Asian immigrant women), with detectable specific SIgA antibody directed against different $E$ coli $\mathrm{O}$ serogroups (crude $\mathrm{O}$ antigens and pure lipopolysaccharide) were tested extensively for cross specificity against other strains represented in the panel. Specific antibody was absorbed from individual milk samples, at the highest dilution giving a positive result to a given $E$ coli antigen, by incubating the samples with various amounts of the respective crude $O$ antigens or lipopolysaccharide (and other O serogroups represented in the panel) for one hour at $37^{\circ} \mathrm{C}$ in a rotating mixer. This was followed by retesting the 'absorbed' milk samples in the respective specific antibody detection assays. All experiments were carried out in duplicate with appropriate positive and negative controls.

\section{Results}

TOTAL SIgA ANTIBODY CONCENTRATION

As expected, there was a wide variation in total SIgA antibody concentrations in each of the three subject groups (up to 36-fold differences), consistent with the known decrease of total SIgA antibody during lactation. There was no 
Table 2 Concentrations of $\operatorname{SIg} A$ in milk

\begin{tabular}{|c|c|}
\hline Subject group & $\begin{array}{l}\text { Median (range) total SIgA } \\
\text { concentration in milk }(g / l)\end{array}$ \\
\hline Sri Lankan women $(n=64)$ & $2 \cdot 34(0 \cdot 3-19 \cdot 1)$ \\
\hline $\begin{array}{l}\text { Asian immigrant women in } \mathrm{UK} \\
(\mathrm{n}=20)\end{array}$ & $3 \cdot 1(0 \cdot 2-16 \cdot 4)$ \\
\hline White women in UK $(n=75)$ & $2 \cdot 5(0 \cdot 2-18 \cdot 2)$ \\
\hline
\end{tabular}

There was no significant difference between the groups.

significant difference $(\mathrm{p}>0 \cdot 05$, Mann-Whitney $\mathrm{U}$ test) in the total milk SIgA concentrations between the three groups of women, however (table 2).

DIARRHOEAGENIC E COLI SPECIFIC SIgA ANTIBODY ACTIVITY

Representative individual profiles

Figure 1 shows $E$ coli $\mathrm{O}$ antigen specific milk SIgA antibody activities of three representative women (one from each subject group). The specific SIgA antibody activity is expressed as absorbance units obtained from the raw data of individual experiments. There was excellent correlation between the results of experiments carried out with crude $\mathrm{O}$ antigens and the
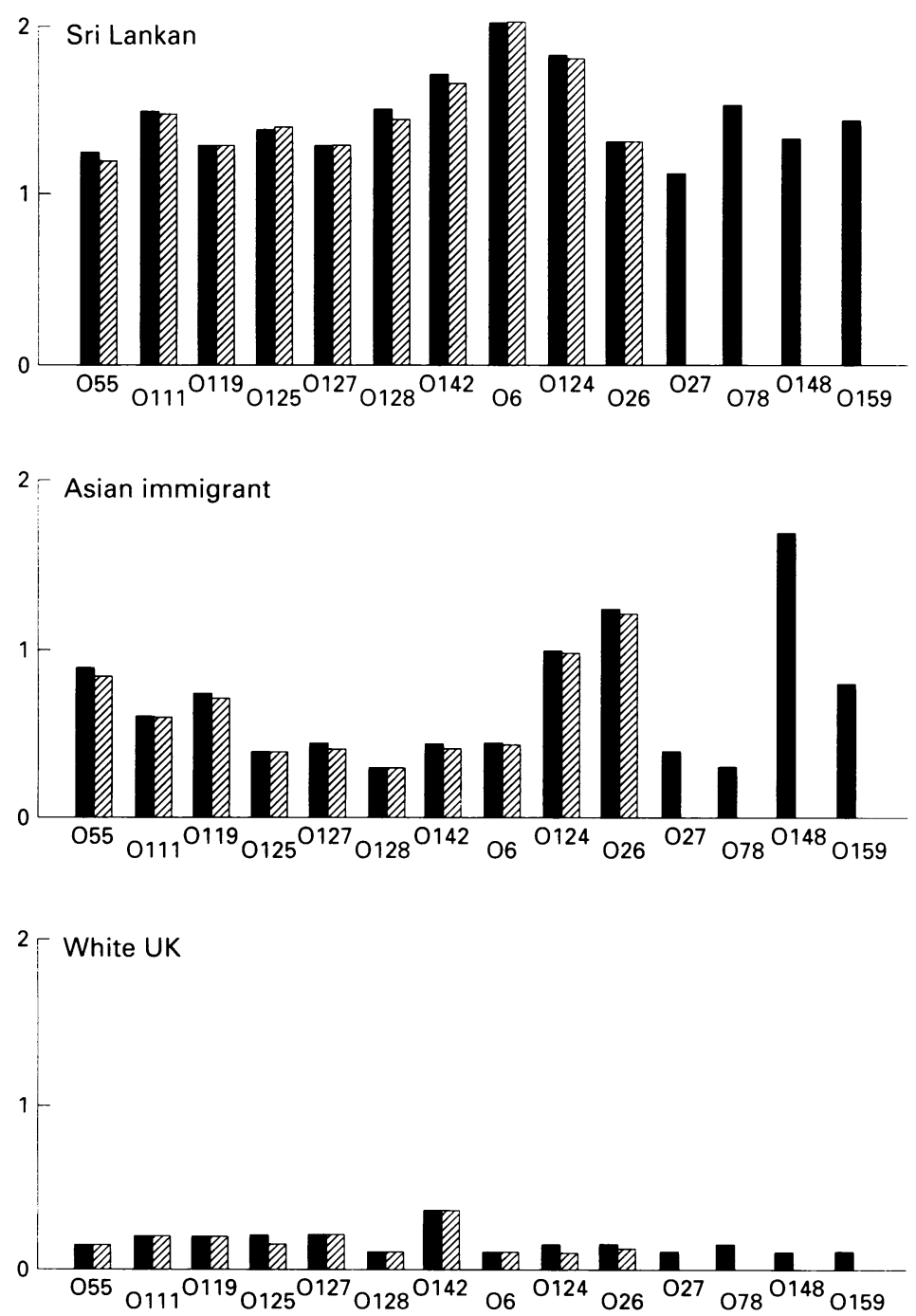

Crude $\mathrm{O}$ antigen $\square \quad$ LPS $\square$

Figure 1 Escherichia coli $O$ antigen specific $\operatorname{SIg} A$ antibody profiles in three representative women (one from each subject group); LPS=lipopolysaccharide. corresponding lipopolysaccharide (fig 1). Three of $64(5 \%)$ Sri Lankan milk specimens that gave a positive result with crude $\mathrm{O}$ antigen did not give a positive result with pure lipopolysaccharide from the corresponding $\mathrm{O}$ serogroup. The reverse phenomenon was not seen. The absorbance correlated well $(r=0.96$, $\mathrm{p}<0.0001$, Spearman's rank correlation coefficient) with the titre of specific SIgA antibody in milk determined by dilution analysis (data not shown).

\section{Group profiles}

The range of specificities of milk SIgA antibody activity to $E$ coli $\mathrm{O}$ antigens was variable in each subject (and between subjects), within each group, and between groups. Figure 2 shows the percentage of women in each of the three groups of subjects with detectable $E$ coli $\mathrm{O}$ antigen specific SIgA antibody activity across the 14 strains used in the panel. The percentage of Sri Lankan and Asian immigrant women with detectable $\mathrm{O}$ antigen specific SIgA antibody activity against all diarrhoeagenic $E$ coli serogroups (except $\mathrm{O} 127$ in Asian immigrants) was significantly higher $\left(p=0.02\right.$ to $<0.00001, \chi^{2}$ test) than in the white 'controls'. There was no statistically significant difference ( $p>0.05)$ between the percentages of Sri Lankan and Asian immigrant women with detectable SIgA antibody activity to all diarrhoeagenic $E$ coli $\mathrm{O}$ serogroups except $\mathrm{O} 125, \mathrm{O} 127, \mathrm{O} 128$, and $\mathrm{O} 142$.

SPECIFIC ANTIBODY ACTIVITY AS A

PERCENTAGE OF TOTAL SIgA

As the concentrations of total SIgA antibody in milk specimens from all three groups of subjects were variable, the measured diarrhoeagenic $E$ coli $\mathrm{O}$ antigen specific SIgA antibody concentration in each specimen was compared with the measured total SIgA antibody concentration by expressing it as a percentage of the total SIgA (fig 3). The Sri Lankan and Asian immigrant women had a significantly higher percentage of $E$ coli $\mathrm{O}$ antigen specific SIgA antibodies (median 6 and $4 \%$ respectively) in their milk compared with their white controls (median $0.7 \%$ ) living in the United Kingdom $(p<0.0001$ and $p<0.001$ respectively, Mann-Whitney $U$ test). There was no significant difference between the percentage of $E$ coli $\mathrm{O}$ antigen specific SIgA antibodies (of total SIgA) in milk of Sri Lankan and Asian immigrant women $(p=0 \cdot 1$, Mann-Whitney $U$ test). In both these groups, the percentage of $E$ coli $\mathrm{O}$ antigen specific SIgA antibody activity did not correlate with the day of lactation in individual women. The titre of specific antibody was higher in the milk specimens collected early in lactation, however (that is, in colostrum).

Neither the titre of specific antibody nor the percentage $E$ coli $\mathrm{O}$ antigen specific SIgA antibody activity in Asian immigrant women correlated with their duration of stay in the United Kingdom. 

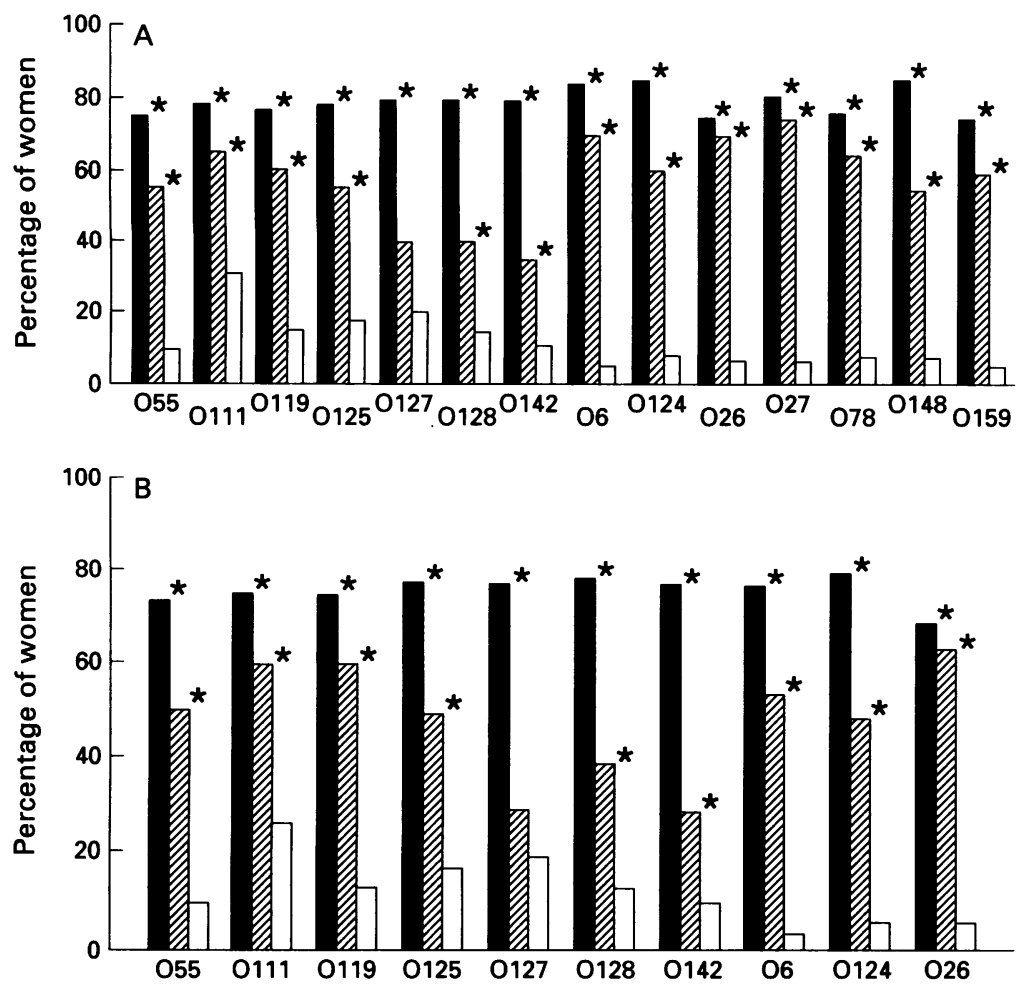

Sri Lankan $\mathbf{D}$ Asian immigrant $\mathbb{Z}$ White UK $\square$

Figure 2 Percentages of women in each of the three groups with demonstrable specific SIgA antibody to the respective $O$ antigens of Escherichia coli in the panel. $(A)$ Results with crude $O$ antigens; $(B)$ results with pure lipopolysaccharide; ${ }^{\star}=$ significant difference between Sri Lankan or Asian subject groups compared with white controls; $p=0.02-0.00001$ ).

\section{E COLI O SEROGROUP SPECIFICITY OF SIgA} ANTIBODIES

Escherichia coli $\mathrm{O}$ antigen specific SIgA antibodies in milk were highly $O$ serogroup specific. A given milk specimen with specific SIgA antibody activity against a given $E$ coli antigen (that is, crude $O$ antigen or pure lipopolysaccharide) could not be absorbed (that is, inhibited from ELISA binding) by exposure to crude $\mathrm{O}$ antigen or lipopolysaccharide of any $O$ serogroup other than the identical crude $\mathrm{O}$ antigen or lipopolysaccharide, or both. Absorption with the homologous $\mathrm{O}$ serogroup antigen(s) was highly effective, however. This was a consistent finding with all 20 milk specimens tested extensively for cross reactivity. Some specimens $(<5 \%)$, however, from Sri Lankan and from Asian women with SIgA antibody activity to a given crude $\mathrm{O}$ antigen, could only be inhibited/absorbed by the identical crude $O$ antigen, but not by the corresponding lipopolysaccharide. Although rare, such findings were not restricted to any particular $E$ coli $O$ serogroup.

\section{Discussion}

This study examined the concept that specific antibody profiles in human milk may represent an epidemiological marker for enteropathogens in a given locality. Because of the known high prevalence of diarrhoeagenic $E$ coli in the Indian subcontinent, ${ }^{25}$ women living in Sri Lanka are likely to have had clinical or subclinical exposure to these organisms, unlike their white counterparts living in the relatively cleaner environment of the UK. The Asian immigrant women were an important group of subjects because of a presumed natural change in their epidemiological environment from previously high exposure to little or no exposure to diarrhoeagenic $E$ coli. Several previous studies $^{12-22}$ have documented SIgA antibodies (to a variety of different enteric pathogens) in milk from women in developing countries. Some studies ${ }^{12-161922}$ suggest that differences in the specific antibody pattern in human milk may be associated with exposure to certain pathogens, perhaps facilitated by poor socioeconomic conditions. We are not aware of any studies that have addressed the question of specific antibodies in milk from migrant populations comparable with the Asian women in this study.

We have shown important qualitative differences between specific SIgA antibody profiles in the two 'study groups' compared with 'controls', despite highly comparable ranges of total SIgA levels in all three groups. The fraction of $E$ coli $\mathrm{O}$ antigen specific SIgA antibody, as a percentage of the total milk SIgA was much higher in the Sri Lankan and Asian immigrant women than in the white controls. This method of data analysis enables logical comparison of results as it eliminates differences due to the widely variable total SIgA antibody concentrations of individual milk specimens in all three groups. The qualitative differences in specific SIgA antibodies to $E$ coli $\mathrm{O}$ serogroups in the milk from Sri Lankan and Asian women could be explained by the known high prevalence of these organisms in developing countries. ${ }^{25}$ The SIgA antibody specificity in human milk could therefore be regarded as an epidemiological

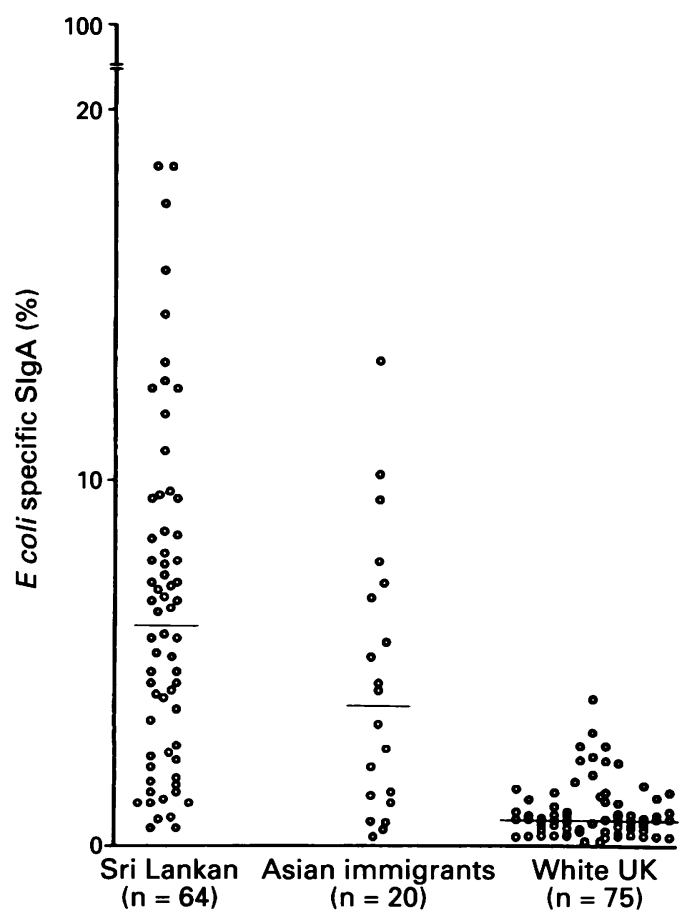

Figure 3 Percentage of diarrhoeagenic Escherichia coli $O$ antigen specific $S I g A$ antibody levels as a fraction of the total SIg $A$ in the three groups. Horizontal bars denote medians for each group. Sri Lankan and Asian immigrant women had significantly higher values $(p<0.0001$ and $<0.001)$ than their white controls in the UK. 
marker of gastrointestinal pathogens in a community. Our data also lend further strong support to the concept of an enteromammary link in the secretory immune system.

The persistence of high titres of specific antibodies in the Asian immigrant women with a median period of residence in the United Kingdom of five years is a new and important observation. Several possible mechanisms, singly or jointly, may explain the continuing specific SIgA antibody response in Asian immigrant women. Firstly, occult/subclinical infection with diarrhoeagenic $E$ coli may persist in the tightly knit Birmingham Asian community, perhaps reinforced by visits by family members to and from their native countries in the Indian subcontinent. Only two of 20 Asian subjects had visited India (for two and four weeks, respectively), however, and both showed low levels of specific antibodies in their milk. Contaminated imported food is another theoretical source of bacterial antigen. Secondly, $O$ antigens may be sequestrated to a component of the host immune system that allows the long term presentation of these molecules or their immunogenic fragments to host lymphocytes, thus perpetuating a specific SIgA response. There is increasing evidence in experimental animals that antigens sequestered onto follicular dendritic cells within the germinal centres of secondary lymphoid tissues has a long life span. ${ }^{26}$ Little is known of the contribution of this mechanism to mucosally expressed immunological memory in humans and still less about the enteromammary pathway of the human mucosal immune system in this context. The potential significance of this mechanism, accessed through the oral route of immunisation, justifies further research. Thirdly, there may be continuing stimulation of the already primed SIgA system of the gut by antigenically cross reactive molecules derived from strains of $E$ coli or other enterobacteriaca, that form part of the natural gut flora. In principle at least, such a mechanism of antigen selection of B lymphocytes with specificity for epitopes shared commonly between microbes would be highly advantageous to the host. It could be envisaged that germinal centres in Peyer's patches and mesenteric lymph nodes might be engaged in the clonally dominant proliferation of plasma cells and memory $B$ cells where emphasis on specificity might be towards commonly encountered microbial antigens. Our data, however, do not support this concept because the specific antibodies to the $E$ coli $\mathrm{O}$ serogroups that we describe showed a remarkable degree of serotype specificity within the several strains of diarrhoeagenic $E$ coli antigens in our panel. We have shown the high degree of $O$ serogroup specificity by using individual purified antigens (lipo- polysaccharide) and also by cross antigen absorption studies. Finally, the continuing stimulation of the already primed SIgA system by anti-idiotype antibodies simulating immunogenic epitopes of $E$ coli antigens is another intriguing possibility that merits future investigation.

The fact that we used individual $O$ antigens (crude and pure lipopolysaccharide) rather than a pool of $E$ coli antigens, which other studies $^{13} 16$ have employed, needs emphasis. The percentages of Sri Lankan and Asian women with specific antibodies to the range of antigens in our panel were broadly comparable. This, however, was not the case with antibodies to $O$ serogroups $125,127,128$, and 142. Local epidemiological differences within countries of the Indian subcontinent may explain these observations. The comparatively wide heterogeneity of the Asian immigrant women, including two from Sri Lanka, and the smaller size of this group (20 subjects) may also contribute to these differences. The proportion of women with specific SIgA antibodies to $\mathrm{O}$ antigens of four ubiquitous strains of $E$ coli were not only highly comparable, but also of uniformly low titre in all three groups (data not shown). The explanation is not known, but may be the result of commonly found commensals of low immunogenicity.

The serum antibody status of our subjects is unknown. The specific SIgA antibodies shown in milk from Sri Lankan and Asian immigrant women, however, is unlikely to be a spillover effect as SIgA is not a circulating immunoglobulin and is synthesised locally in the mammary gland. ${ }^{27}$ Pregnant women clinically infected with Salmonella typhimurium have been shown to have specific SIgA antibody in their mammary secretions, whereas the only specific antibody demonstrable in their serum was of the IgG class. ${ }^{6}$ In another study three pregnant women experimentally infected with $E$ coli $\mathrm{O} 83$ had antibody secreting cells in their mammary secretions but no detectable specific serum antibody. ${ }^{8}$ None of the $E$ coli $\mathrm{O}$ serogroups used in our study (except O124) is known to invade the gut mucosa. Therefore the mammary lymphoid tissues of the Sri Lankan and Asian immigrant women are unlikely to have encountered the intact $E$ coli antigens used in the present study. The most likely mechanism of transfer of immunological specificity to the mammary glands of these women is therefore by way of specifically sensitised lymphocytes (preplasma cells) originating in the gut. This view is endorsed by several studies. ${ }^{1-9}$

We conclude that the specific SIgA antibody profile in human milk reflects the enteropathogens encountered in a community. This phenomenon enables human milk to provide its widely known passive protection to infants against gastrointestinal infections. The continuing presence of $O$ antigen specific SIgA antibodies to diarrhoeagenic $E$ coli in Asian immigrant women strongly suggests the possibility of immunological memory in the human secretory immune system. Further studies involving a larger group of subjects, preferably of less diverse origin, from the Indian subcontinent, are required, both to confirm our observations and to determine the underlying mechanisms.

We acknowledge the help of nursing and midwifery colleague at the milk bank of the Sorrento Maternity Hospital Birmingham, Birmingham Maternity Hospital, and severa hospitals in Colombo and Kalutara, Sri Lanka for their help with collection of milk specimens for this study. KAN was supported by a scholarship from the Association of Commonwealth Universities and the British Council. 
1 Gowans JL, Knight EJ. The route of recirculation of lymphocytes in the rat. Proc $R$ Soc Lond (B) 1964; 159: 257-82.

2 Montgomery PC, Rosner BR, Cohn J. The secretory antibody response. Antibodies induced by dinitrophenylated type 111 pneumococcus. Immunology Communications 1974; 3: 143-56.

3 Roux ME, McWilliams M, Phillips-Quagliata JM, WeiszCarrington P, Lamm ME. Origin of IgA secreting plasma Carrington P, Lamm ME. Origin of IgA secreting plasma
cells in the mammary gland. $f$ Exp Med 1977; 146: cells in the

4 Weisz-Carrington P, Roux ME, Lamm ME. Plasma cells and epithelial immunoglobulins in the mouse mammary gland during pregnancy and lactation. F Immunol 1977; 199: 1306-9.

5 Weisz-Carrington P, Roux ME, McWilliams M, PhillipsQuagliata JM, Lamm ME. Organ and isotype distribution of plasma cells producing specific antibody after oral immunisation. F Immunol 1979; 123: 1705-12.

6 Allardyce R, Shearman B, McClelland DBL, Marwick K, Simpson AJ, Laidlaw RB. Appearance of specific Simpson AJ, Laidlaw RB. Appearance of specific
colostrum antibodies after clinical infection with Salmonella typhimurium. BMF 1974; 3: 307-9.

7 Dunkley ML, Husband AJ. The induction and migration of antigen-specific helper cells for IgA responses in the intestine. Immunology 1986; 57: 379-85.

8 Goldblum RM, Ahlstedt S, Carlsson B, et al. Antibody forming cells in human colostrum after oral immunisation. Nature 1975; 257: 797-9.

9 Czinn SJ, Lamm ME. Selective chemotaxis of subsets of B lymphocytes from gut-associated lymphoid tissue and its implications for the recruitment of mucosal plasma cells. implications for the recruitment

10 Falth-Magnusson $\mathrm{K}$. Breast milk antibodies to foods in relation to maternal diet, maternal atopy and the development of atopic disease in the baby. Int Arch Allergy Appl Immunol 1989; 90: 297-300.

11 Joto P, Holm S. Gliadin-specific and cow's-milk specific IgA in human milk. $\mathcal{F}$ Pediatr Gastroenterol Nutr 1992; 15: 159-62.

12 Achi R, Dac Cam P, Forsum U, et al. Titres of class-specific antibodies against shigella and salmonella lipopolysaccharide antigens in colostrum and breast milk of Costa Rican, Swedish and Vietnamese mothers. F Infect 1992; 25: 89-105.

13 Carlsson B, Ahlstedt S, Hanson LA, Lindin-Janson G, Lindblad BS, Sultana R. Escherichia coli O antigenspecific antibody content in milk from healthy Swedish mothers and mothers from a very low socio-economic group of a developing country. Acta Paediatr Scand 1976; 65: 417-23.

14 Cleary TG, Stewart-West M, Ruis-Palacios G, et al. Human milk secretory immunoglobulin A to Shigella virulence plasmid-coded antigens. F Pediatr 1991; 118: 34-8.

$15 \mathrm{Cruz}$ JR, Arevelo C. Fluctuation of specific SIgA antibodies in milk. Acta Paediatr Scand 1985; 74: 897-903.

16 Cruz JR, Carlsson B, Garcia B, et al. Studies in human milk II. Secretory IgA: quantity and antibody levels against Escherichia coli in colostrum and milk from underprivileged and privileged mothers. Pediatr Res 1982; 16: 272-6.

17 Cruz JR, Carlsson B, Hofvander Y, Holme DT, Hanson LA. Studies of human milk 111. Concentration of antibodies against salmonella and shigella in milk of women from different populations and the daily intake by their breast fed infants. Acta Paediatr Scand 1985; 74: 338-41.

18 Grundy MS, Cartwright-Taylor L, Lundin L, Thors C, Huldt C. Antibodies against Entamoeba histolytica in human milk and serum in Kenya. 7 Clin Microbiol 1983; 17: 753-8

19 Holmgren J, Hanson LA, Carlsson B, Lindblad BS Rahimatoola J. Neutralising antibodies against $E$ coli and Vibrio cholerae enterotoxins in human milk from a developing country. Scand $\mathcal{F}$ Immunol 1976; 5: 867-71.

20 Mata LJ, Wyatt RG. The uniqueness of human milk. Host resistance to infection. Am $\mathcal{F}$ Clin Nutr 1971; 24: 976-86.

21 Roiz-Palacios GM, Calva JJ, Pickering LK, et al. Protection of breast fed infants against campylobacter diarrhoea by antibodies in human milk. $\mathcal{f}$ Pediatr 1990; 116: $707-13$.

22 Zaman S, Carlsson B, Morikawa A, et al. Poliovirus antibody titres, relative affinity, and neutralising capacity in body titres, relative affinity, and neutralising capacit
maternal milk. Arch Dis Child 1993; 68: 198-201.

23 Kauffman F. The serology of the coli group. $\mathcal{F}$ Immunol 1947; 57: 71-100.

24 Wood GM, Trejdosiewicz LK, Losowsky MS. ELISA for measurement of secretory IgA distinct from monomeric IgA. F Immunol Methods 1987; 97: 269-74.

25 Levine MM. Escherichia coli that cause diarrhoea. f Infect Dis 1987; 155: 377-89.

26 MacLennan CM, Liu YJ, Oldfield S, Zhang J, Lane PJL. The evolution of B-cell clones. Curr Top Microbiol Immunol 1990; 159: 37-63.

27 Carlsson B, Gothefors L, Ahlstedt S, Hanson LA, Winberg $\mathrm{J}$. Studies of Escherichia coli $\mathrm{O}$ antigen-specific antibodies in human milk, maternal serum and cord blood. Acta Paediatr Scand 1976; 65: 216-24. 